\section{A 速escription}

\author{
OF THE
}

\section{MODE OF TREATING CONSTITUTIONAL SYPHILIS BY SYPHILISATION : AND ITS RESULTS.}

\author{
BY \\ PROFESSOR W. BOECK, M.D., \\ Christiania.
}

IN continuation of the communications which $I$ gave some time ago in the British Medical Journal concerning syphilisation, I will now explain how syphilisation is practised upon children.

During the first years in which I practised syphilisation, I feared to try it on children. It was only after I had seen in more than a hundred cases the salutary effect it exercised upon grown up people, that I ventured to carry the primary syphilitic virus over to children suffering from acquired syphilis; and $I$ confess that $I$ did it at first with great anxiety. I expected to see ulcers of about the same size as those upon grown up persons; and I feared that these ulcers, with their abundant secretion, might exhaust the child entirely. It therefore surprised me to find that the ulcers upon the child were far smaller; they were neither so extensive nor so deep, and secreted but little. I found also, with the child, that matter cannot generally be carried through any long series of inoculations. It is a great deal to be able to make six or seven successive inoculations with the same matter: it therefore becomes necessary to change the matter frequently.

With children, also, I begin the inoculation at the sides. There is not, however, the same thing to be observed as with grown up persons. The ulcers will not be so much larger on the thighs than on the sides, if the inoculations be commenced on the thighs; and I have never seen any tendency to phagedæna in the ulcers, wheresoever I have commenced the inoculations.

The time required for the treatment is about the same with children suffering from acquired syphilis as with grown up people, perhaps somewhat shorter and, with respect to their general health, the case is just the same in both. The children thrive during the treatment, and are as healthy and look as well after it as any one can possibly wish. As far as I have been able to observe these children afterwards, I have found their state of health very satisfactory.

The number of children under three years of age with acquired syphilis, who have hitherto been treated with syphilisation, is twenty-three. Of these, one died of croup after my performing tracheotomy. Of the remaining twenty-two, three have had a relapse but only one of these has been syphilised a second time, the other two having been treated by external remedies.

The results of the treatment of children suffering from hereditary syphilis I have already given once before in the Journal. I shall, therefore, only mention one point in the treatment, in which this form differs from syphilisation in general. As a general rule, there will be no positive result obtained from the first inoculations with children; and, if the inoculations were continued as with grown up persons, or with children suffering from acquired syphilis, and performed only every third day, no result at all would be obtained. It is requisite with these children to inoculate more frequently. I do it myself every day; and then, at the end of six or ten days, I find a commencement of small pustules; and, when the pustules from the last inoculation are being developed, several of the previous inoculations will bring forth pustules at the same time, which will be developed along with those last formed. If the inoculated matter cannot be made to take at all, we may be quite sure that the child will die. It is, therefore, a good sign when the matter takes; but we are not quite safe yet, for it will happen sometimes that pustules begin to fail again after a couple of days. It is, therefore, necessary to observe the pustules every day ; and, if they do not progress continually, inoculations with new matter must be repeated daily. When in this manner well developed pustules, three days old, have been produced, inoculations from these may be begun; but, at the outset, we must not expect to be able to make any series of inoculations-fresh matter will be required for every new inoculation. It is only when the treatment is somewhat advanced, that it will be found possible to carry each matter through a series of some length.

The time necessary for the treatment of children suffering from hereditary syphilis will be nearly four months.

The same difficulty which we find, as a general rule, in the inoculation of children suffering from hereditary syphilis, will also be met with now and then in grown up people suffering from a violent eruption of a syphilitic exanthem. In such cases, inoculation may be sometimes repeatedly performed without any result; but, by going on inoculating every day for some time, small pustules will at last be developed, after which syphilisation will pursue its regular course. In these cases, it is evident that the inoculations made during the first days of treatment have not been without effect. It is also impossible that the inoculated virus should have vanished; it must have been absorbed; and, by the aid of the influence it has exercised, the later inoculations will be enabled to cause a reaction that will admit of the formation of pustules. According to this experience, we might ask whether there exist individuals insusceptible of vaccine matter (without having ever been vaccinated before); or whether it might be possible, by continued inoculations, to produce vaccine pustules.

I shall now go on to another point that has already been mentioned, but not sufficiently explained; viz., syphilisation practised upon persons who have had a relapse of syphilis after a preceding mercurial treatment. Experience has provided us with two facts, which must be placed side by side.

1. When we syphilise individuals suffering from constitutional syphilis, and who have not been previously treated with mercury, we shall invariably find that the inoculations will call forth a series of pustules and ulcers, which will be essentially similar in all persons inoculated; the phenomena of constitutional syphilis will disappear with a regularity and a certainty rarely imitated in the treatment of other diseases.

2. On syphilising individuals who have been previously treated with mercury, we find neither the same regularity in the development of pustules and ulcers, nor the same influence on the syphilitic phenomena; and this will be still more the case in proportion as we get farther away from the primary 
affection, and the longer and more effective the mercurial treatment has been.

In either case there is, however, one thing certain - viz., the salutary influence of syphilisation upon the organism. We often find, during the first development of constitutional syphilis, an anæmic stateweakness, sleeplessness, and headache ; these phenomena will disappear under continued inoculation, and the patient will recover the state of health in which he was before he was attacked by syphilis. Many will, perhaps, be unwilling to give the credit of this amelioration of the general health to the inoculations. They may pretend that a similar result can be obtained by the mercurial treatment; and really they may have some reason to say so, for we often see such cases apparently improving for some time under mercurial treatment; but this result is not constant. Often, on the contrary, we find these cases becoming considerably worse under mercurial treatment; and, by continuing the cure by the ancient method, we see them go continually downwards; whereas, under syphilisation, every patient will invariably go on improving in health.

If we look at another series of cases-the tertiary ones-which have been treated for years with mercury, iodide of potassium, and everything that science had hitherto at her disposal, without any improvement-nay, on the contrary, the local phenomena becoming gradually worse step by step, and the organism, on the whole, declining fast, till there remains but little hope of life;-if, I say, in such cases, syphilisation can be made to improve the general health, then there can be no doubt of its powerful and salutary influence. It is impossible that the previous treatment with what is called specifics should have caused the change; for it has been but too evident that the patient, by the use of these means, has become continually worse. It must needs be the inoculation of the fresh matter that has produced the result. Under any other circumstances, it might be possible to doubt. If, for instance, any one were to say of the constitutional cases, that it is Nature that cures them, and that it is a mere delusion that it should be syphilisation that does it; or if they were to say that syphilis is nothing but a derivation, and that just the same effect would be produced by the use of antimonial plaster, it would not be easy to prove that, in this special case, the syphilitic phenomena would not have disappeared without the use of syphilisation; for we know very well that, in a number of cases, syphilitic exanthemata will disappear witbout anything whatever being used; and so the same thing may happen on using an indifferent means, such as the antimonial plasters. If mercury has been used, and there is a relapse, nobody will deny that the new symptoms may be made to disappear by the use of iodide of potassium; and in the same way the influence of syphilisation may be disputed in every single case, till we come down to those where everything else has been tried in vain. If syphilisation can do something here, it must be acknowledged that it is a new and powerful remedy; and I am going to prove this by quoting sotne cases, after having mentioned the practical result of syphilisation in these cases.

I have already observed, that there is some chance of syphilisation pursuing a regular course even in these cases; but, as a general rule, there will not be the same regular development of pustules and ulcers, and especially not the regular series from the first inoculations, in these old cases, that there will be where mercury has not previously been used, and where the treatment has been commenced immediately after the appearance of the constitutional phenomena. We must be prepared to see the first matter produce but little effect, perhaps none. Inoculation will have to be made over and over again before there will be any development of larger pustules and ulcers; and at first the series of pustules and ulcers will, perhaps, be but a very short one. New inoculations do not take; and the patient seems, after a short time, to be quite proof against syphilisation. Under these circumstances, there is nothing else to be done than to wait for some time. After a few weeks, it may happen that the patient will again be susceptible to some inoculations. We may even find that the next series of inoculations will be longer than the first one. If the inoculations refuse altogether to be carried through a new series, some iodide of potassium must be given; after some doses of which, the inoculations will sometimes be seen to succeed again; and we also shall find that, after a continuance of syphilisation, iodide of potassium will exercise considerable influence, where perhaps, before syphilisation, it would do nothing at all. The result of our treatment in these old cases is very uncertain. In some cases, it will succeed very well; in others, it will hardly do anything at all ; and often, when we think that the phenomena are nearly disappearing, there will be a new eruption. We need to be very cautious with respect to their prognosis.

The time required for syphilisation in old cases differs greatly in different cases; but, as a general rule, it will be very long, because there is no question of a continued series of inoculations, but of several series with shorter or longer intervals. But, even if the inoculations take systematically, it may require a long time.

A woman, G. M. S., aged 30, entered the hospital on the 8th of October, 1852. The lower part of the nose was very much swollen, and covered with a great many small round crusts. On some places, where the crusts had fallen off, the skin underneath was very red. All round this crusted place, the skin was evenly swollen. There were some isolated tubercles, of about the size of a pea, and covered with white scales. On the right side of the nose, and extending partly to the cheek, there was a circular ulcer, of about the size of a shilling, with sharply cut edges, a concave uneven surface, and a dirty yellowishgreen secretion. The surrounding skin, to the extent of half an inch, was copper-red, thick, somewhat rough, and covered with crust, partly of a round, partly of an irregular form. That part of the mucous membrane next to the openings of the nose was partly excoriated, partly covered with a yellowishgreen secretion; the other part of the mucous membrane was bright red, swollen, and secreted a thin watery mucus. On both forearms and on the left leg, there were a great many large, round, deep ulcers, with sharply cut edges and abundant secretion.

She had been previously treated in the hospital from June 13th, 1851, till July 15th, 1852. 'The symptoms from which she then suffered were: tubercula mucosa of the genital organs; a papulo-tuberculous exanthem extending over the whole body; affection of the throat; and withal an anæmic state. She had been treated with corrosive sublimate, iodide of potassium, mercurial inunctions, and liquor Bellosti.

The treatment was commenced on October $17 \mathrm{th}$, 1855, with iodide of potassium, which was at last given her in large doses. After having used iodide of potassium for more than five months, there was still a papulous exanthem on different parts of the face. The iodide of potassium was then stopped; and on April 2nd, 1853, she began aurum muriaticum natronatum (chloride of gold and sodium), which she continued for six weeks without any improvement. On the contrary, the above mentioned exanthem on 
the extremities broke out again worse than ever. The gold was therefore also stopped; and she began a water-cure, with which she went on for two months, during which time the large ulcers on the extremities were healed; but there still remained a great many tubercles of various size, the tops of which were covered with crusts. The development of tubercles was, however, worst on the face; the nose, cheeks, and upper lip being entirely covered with them. These same places were also hypertrophied; and on the alæ nasi there were phagedænic ulcers, which had already destroyed part of the substance. She was very like one suffering from elephantiasis Græcorum. Her general health was very bad; she was very weak, and always confined to bed.

On August 10th, 1853, syphilisation was commenced; and the inoculations in this case looked uncommonly well. Already, at the end of three weeks, the tubercles and ulcers of the face began to diminish. This improvement went on; and, at the end of six weeks, the ulcer on the nose was healed; but at the same time the ulcers of the right leg became worse, and were not healed until two months later. Seven months after syphilisation had been commenced, new ulcers appeared on the right leg; which, however, cicatrised after three weeks. For some time yet the inoculated matter continued to take but indifferently, all the syphilitic phenomena having vanished by degrees. Her general health, which had been gradually improving during the syphilisation, was excellent when she was dismissed from the hospital as cured, on July 26th, 1854. I have seen her several times since; and she has always expressed her particular satisfaction with the treatment.

It may be said that the treatment in this case was a very long one. But, when one takes into consideration that, after a still longer continuance of another treatment, the result had only been an aggravation of the local phenomena as well as of the general health, I think that no fault should be found with the length of time required for syphilisation. It must also be observed, that this case is the only one in which the treatment by syphilisation is known to have been so long.

It ought also to be mentioned, that she most anxiously asked to be syphilised, because she saw others lying in the same room with her improving much by being treated by syphilisation.

[To be continued.]

The Use of Alcomol. There can be little doubt but that the promiscuous prescribing of alcoholic drinks to patients by the medical profession has been the source of much drunkenness, disease, and death; and only by the astounding declarations made upon the temperance platform, by men who had experience alone for their guide, has the attention of the physiologist and the chemist been drawn to investigate the stion of alcohol from a scientific point of view. So

teresting, indeed, has become the inquiry, that medieal men in England, America, France, Germany, and other countries, have lent their aid to solve the question whether the use of alcohol is, or is not, beneficial to the human body. Until very recently the medical press of the metropolis abounded with articles unfavourable to the total abstinence question, scientifically proving that alcohol was a necessary adjunct to the diet of man; but during the last few years medical men of talent and bigh standing in the profession in the provinces, as well as in the metropolis, have made the physiological action of alcohol a study, and have put forth many new and unanswerable deductions, proving that alcohol, as an article of diet, is always dangerous, and only to be taken under medical supervision. (Dr. Munroe.)

\section{dodoresses and 籍apers \\ READ AT}

\section{THE THIRTY-THIRD ANNUAL MEETLNG OF THE BRITISH MEDICAL ASSOCIATION.}

[Held in LEA.IINGTON, AUGUST 1st, 2nd, 3rd, and $4 t h, 1865$.

\section{A CASE OF PROGRESSIVE MUSCU. LAR PARALYSIS, CHIEFLY OF THE PHARYNX, LARYNX, AND TONGUE.}

\section{By JOHN K. SPENDER, Esq., Surgeon to the} Eastern Dispensary, Bath.

E. B. came under my notice as a patient at the Eastern Dispensary, Bath, on March 10th, 1862. He was a tall thin young man, 20 years old, with a pale and anxious countenance. $\mathrm{He}$ was so weak that $\mathrm{I}$ requested him to return home and go to bed, where I saw him a day or two after.

His history in brief was : that up to 10 years of age he was a remarkably short fat boy; that then he began to grow fast, and always ate verr ravenously; and he attained his present stature of five feet ten inches when he was not quite 17 years old. Soon he became very thin, and proportionately weak-the thinness arising seemingly from loss of fat and loss of muscle; but he was able to work, and he had not suffered from any serious illness before he applied to me.

His chief complaint was of pain in the back, and of some numbness in the legs. I was informed that he had recently had two or three strange "fits," which I judged to be of an epileptoid character ; they consisted of a short but complete insensibility, accompanied by a gurgling noise in the throat. There had been a progressive loss of power in the legs for some months, with impairment of the co-ordinating faculty.

The most noticeable symptom now, was a difficulty in swallowing solid food. 'This was the predominant and most distressing symptom throughout; and for a period of more than eight months before death, scarcely anything was swallowed except sugar dissolved in water. This he liked and craved for; about two or three pounds of sugar were consumed in a week. Now and then at rare intervals, he took a little tea and milk, but with evident nervous trouble; and when I persuaded him one day to try and swallow some biscuit powder and water, a fearfully suffocative spasm of the pharyngeal and laryngeal muscles was provoked, and he barked like a dog for several minutes. He had always pain in talking; his articulation was imperfect, because he could not make his lips meet; and he seldom spoke, except to express an urgent want.

There was no saliva in his mouth; his tongue at first was covered with white fur, but at length became very red and dry, and finally got exceedingly small in size. The pulse and respiration did not vary much, and bore to each other their usual ratio. The bowels were never moved without an injection of soap and water, which came away with a slight tinge of fæcal matter. The average daily amount of urine was half a pint; its specific gravity was low, but in other points it was not abnormal. Nutrient enemata of port wine and beef-tea were not retained for a moment. The wasting was general and excessive, and was especially noticeable about the throat. A month 